\title{
Entre retratos e cadáveres: a fotografia na Guerra do Paraguai
}

\author{
André Amaral de Toral \\ Doutor em História Social pela FFLCH-USP
}

RESUMO

Oregistrofotográfico da guerra do Paraguai contra a Tríplice Aliança (1864-1870)foi, em termos gerais, uma continuidade do tipo de fotografia que se fazia na época. Mas foi, também, mais do que isso. A cobertura in loco e a força do assunto trouxeram maneiras inovadoras de se representar o conflito, o que colaborou para a constituiçấo de uma linguagem fotográfica com características próprias em relaçãoà pintura ou gravura doperíododedicadasàguerra.

Palavras-chave: Guerra da Tríplice Aliança; GuerradoParaguad; Fotografia do séculoXXX; Foto-jornalismo.

\begin{abstract}
Photographic registers of the Triple Alliance War (1864-1870), which involved Brazil, Argentina and Uruguay against Paraguay, were, in a general sense, part of the same genre of commercial photography from the period. But it were, also, more than this. The work at the field, among armies and corpses, brought new manners of seeing the war and developed the photography as autonomous visual language, with many differences comparing with paintingor engraving.
\end{abstract}

Keywords: Triple Alliance War; Paraguay's War; XIX century photography; Photo-journalism.

\section{A TRANSCENDÊNCIA AO ALCANCE DE TODOS}

Apartir da invenção do daguerreótipo em 1839, impressão da imagem em metal, a fotografia deixou de ser apenas experimentação e tornou-se atividade profissional.Já a partir de 1842, daguerreotipistas norte-americanos anunciavam seus serviços no Brasil; em 1847, oAlmanaque Laemmert anunciou trêsoficinas especializadas no Rio de Janeiro'.

Odaguerreótipo, que só permitia um original montado como jóia em estojos especiais, teve, no entanto, circulação restrita. A 
técnica que permitiu a expansão da fotografia nas décadas de 1860 e 1870 foi a "dobradinba", negativo de colódio úmido e cópia sobre papel albuminado ${ }^{2}$. A elaboração de um negativo à base de colódio sobre chapas de vidro ou metal e a possibilidade de produção de múltiplas ampliações sobre papel agilizou a produção e reprodução de registros fotográficos, possibilitando um rentável aproveitamento comercial.

A reprodução de sua própria imagem, antes privilégio dos que podiam fazer-se retratar por um artista, amplia-se para um público mais amplo. A partir de 1854, popularizam-se pequenos retratos, chamados carte-de-visite por terem o tamanbo de um cartáo de visita. Eram destinados a serem oferecidos a amigose parentes com indefectíveis dedicatórias escritas no verso onde aparecia como prova de amizade, despedida, saudação ou simplesmente para marcar um compromisso.

O costume, comum nos dias de boje, de se trocar retratos com pessoas significativas, ou de colecioná-los, uma vez que não bavia publicação de fotografias, formou-se explosivamente entre 1850 e 1870. A descoberta da disponibilidade da própria imagem, para um público que nunca tinba tido acesso a um retrato, era uma coisa quase mágica, que ia além daquilo que se considerava possível. Por intermédio da fotografia, cada família tinba possibilidade de construir uma crônica de si mesma, "coleção portátil de imagens que testemunba sua coesão"s.

Boris Kossoy afirma que "o retrato apresentado dessa forma tornou-se a moda mais popular que a fotografia assistiu em todo o século passado”. Seu amplo consumo traria a padronização do produtofotográfico e de seu conteúdo, estereotipando cenários e poses dos retratadost.

A troca de cartóes e o problema de como acondicioná-los daria início aos álbuns de fotografias, destinados aos temas mais diversos comofamília, amigos, autoridades e personalidades, paisagens, tipos bumanos pitorescos, guerra, erótico etc.

Como resultado da popularidade dos carte-de-visite, multiplicavam-se os estúdios na maioria das capitais européias e, principalmente, nos Estados Unidos. Para se ter uma idéia da rapidez do processo, nesse último país, o total de fotógrafos passa de $938 \mathrm{em}$ 
1851 para 7.558 em 1870. Em Londres, os 66fotógrafos de 1855 aumentaram para 284 em 1866. Em Paris, em 1861, 33 mil pessoas viviam da produção de fotografias. Chegando a um tal grau de desenvolvimento do mercado produtor de fotografias, era de se esperar que pelo menos uma parte desse grande número de profissionais se voltasse à exploração de mercados ainda não saturados.

Todas as capitais dos países envolvidos na guerra do Paraguai, e boa parte de suas províncias, receberam a visita desses profissionais itinerantes vindos da Europa e dos Estados Unidos, que se anunciavam pela imprensa e partiam depois de "fazer a praça". Aomesmo tempo que executavam seus retratos, procuravam registrar costumes ou lugares, para aproveitamentofuturo, como material de gênero pitoresco, vendidas em álbuns ou foto por foto, no seu retorno aos seus países de origem.

O Rio de Janeiro, embora em parâmetros mais modestos, também experimentou um crescimento no seu número de fotógrafos: 11 em 1857 e 30 em 1864'. Em 1869, o primeiro censo nacional da Argentina registrou 190 fotógrafos no país, 130 dos quais concentrados em Buenos Aires'. Montevideo, que lucrava com os fornecimentos para a guerra, também atraiu um bom número de fotógrafos entre 1863 e 1870. O Paraguai, mais isolado, recebeu, entre 1846 e 1870, cerca de sete fotógrafos itinerantes: norteamericanos, franceses, italianose ingleses. Apenas um deles, Pedro Bernadet, ao que se sabe, chegou a estabelecer estúdio em Asunción, entre 1865 e $70^{8}$.

Dos muitos estúdios atuantes no Brasil na segunda metade do século passado, vale destacar, utilizando-se os levantamentos de Bóris Kossoy, em São Paulo, o de Militão Augusto de Azevedo, Renouleau, Carlos Hoenen; no Rio, capital da fotografia no Império, os de José Ferreira Guimarães, Joaquim Insley Pacheco, Carneiro \& Gaspar, Alberto Henschel \& Cia.; em Salvador, Lindemann, Wilbelm Gaensly, João Goston; no Recife, Augusto Stabl, João Ferreira Villela, Labadie; em Porto Alegre, Luiz Terragno, Virgílio Calegari, entre outros?.

Movendo-se entre as capitais de províncias do Brasil e da Argentina, esses fotógrafos, cujo trabalbo em boa parte permanece anônimo, produziram considerável quantidade de retratos de 
autoridades, tiposhumanos utilizados parafotografias de gênero pitoresco (muito próximas das pinturas e desenbos de mesmo gênero) como indios e negros, soldados e principalmente de bomens e mulberes de classes médias urbanas. Na Argentina, noUruguai e no Brasil, os estúdios encontravam-se, em sua maioria, nas mãos de estrangeiros, principalmente norte-americanos, alemães, portugueses efranceses.

Além dos retratos, no mundo inteiro, um outro gênero de fotografias de paisagens urbanas e da natureza, panoramas, tipose lugares pitorescos, vendidas unitariamente ou em tiragensmontadas comoálbuns também tiveram grande aceitação. Seu formato podia ser o de carte-de-visite ou o cabinet size, um pouco maior.

Afotografia desenvolveu-se como atividade comercial particular, sendo muito poucos os casos em que foi subvencionada por governantes. O único trabalbo que recebeu apoio oficial, embora nenbuma subvenção, foi no Uruguai, onde uma firma norte-americana teve apoio para documentação da guerra do Paraguai.

Surpreendentemente, mesmo no Brasil, onde o imperador 286 erafotógrafo amador e colecionador, a fotografia recebeu pouco apoio oficial. D. Pedro II conbecia os trabalbos dos profissionais mais renomados estabelecidos no Rio de Janeiro ou que visitavam a cidade. Fez-se retratar por boa parte deles. Concedeu o título "fotógrafo da Casa Imperial" a mais de duas dezenas de fotógrafos entre 1851 e $1889^{10}$. Toda sua coleção particular, intitulada Coleçáo Teresa Cristina, com mais de vinte mil fotos, foi doada, após a proclamação da República e o exílio, à Biblioteca Nacional e ao Museu Nacional principalmente.

Fala-se muito no "mecenato" do Imperador" mas, além de colecionador e entusiasta conbece-se apenas um fotógrafo que D. Pedro II teria apoiado efetivamente como "mecenas". Entre 1857 e 1862, gastou cerca de 12 contos e 27 mil réis por um trabalbo de Victor Frond, um francês que tinba o projeto de fotografar os "cantos mais longínquos do Império". Até boje, não se conbece nenbum original do trabalbo, apenas as litografias feitas a partir das fotos que se encontram no álbum "Brasil Pittoresco", impresso em Paris. 
O CARTE-DE-VISITE VAI À GUERRA

Énesse quadro de crescimento da importância comercial da fotografia que se deve ser buscar as origens do tipo de cobertura dada à guerra do Paraguai. Como se deduzfacilmente, a maior parte da documentaçãofotográfica da guerra é representada pelos milhares de carte-de-visite de soldados a generais feitos entre 1864 e 1870. As melbores coleçóes de material fotográfico sobre a guerra sáo os álbuns, formados de carte-de-visite dedicados ao tema, que se salvaram no tempo.

De novembro de 1864 até ofinal do ano seguinte, as declarações de guerra do Paraguai, seguidas de invasóes ao Brasil è à Argentina, causaram uma onda de indignação na opinião pública desses dois países. Exigia-se uma resposta militar. Mitre e D. Pedro I experimentaram um efêmero momento de grande popularidade, como defensores de seus respectivos países, ameaçados por um ataque "traiçoeiro", embora perfeitamente esperado.

Osfotógrafos aproveitavam esse clima de patriotismo inicial que imperava nas capitais dos países que formariam a Tríplice Aliança. Em praticamente todas as cidades havia muita procura de retratos dos soldados que partiam para a guerra ou que já se encontravam em campanba.

Diversos estúdios ofereciam retratos dos governantes que formavam a Aliança, ou carte-de-visite de personagens políticos ou comandantes militares, vendidos separadamente. Nosjornais do Brasil e da Argentina, anunciavam-se descontos especiais para retratos de soldados.

Esse clima contagiou até o severo D. Pedro II que, como muitos outros soldados, fez-se retratar em trajes militares, "uniforme de gala e traje de campanba", em dois carte-de-visite feitos por Luiz Terragno, em 1865, provavelmente em Porto Alegre. Procurando dar o exemplo como "primeiro voluntário da pátria", o imperador brasileiro tentava se identificar com o cotidiano de soldados e oficiais, ao menos nos seus sinais exteriores, como vestir uniforme e tirar fotografias.

A guerra, evidentemente, era um grande negócio para osfotógrafos. Enaquele momento, era a mellbor coisa aparecida desde a invenção do carte-de-visite. O conflito inaugurou uma competi- 
çãoferoz ${ }^{12}$ entre os fotógrafos que disputavam o enorme mercado, representado pelos milhares de soldados. Durante todo o período de mobilização de tropas, esses profissionais fizeram excelentes negócios, fotografando os jovens soldados em seusflamantes uniformes.

Aquantidade de carte-de-visite retratando militares no mundo inteiro, a partir de 1860, foi táo grande que chegou a marcar, segundo alguns autores, o surgimento da fotografia militar. Nesse aspecto, a guerra do Paraguaifoi a maisfotografada da América, de forma similar à guerra da Secessáo nos Estados Unidos ${ }^{13}$.

Aguerra, de resto, já servia como tema àfotografia bá bastante tempo. A produçáo de retratos e de paisagens, cenas dofront $e$ outros temas militares iniciou-se provavelmente com os daguerreótipos sobre a guerra entre México e Estados Unidos (184648), prosseguindo depois com as guerras Sikb (1848-49) na Índia inglesa, guerra da Birmânia (1852), guerra da Criméia (1854-56), onde Inglaterra, França e Turquia hutaram contra a Rússia, rebelião dos Cipaios ou Indian Mutiny na Índia inglesa (1857-59) e finalmente, a guerra civil norte-americana (1860-65) $)^{14}$. Correspondentesfotográficos do The Times e do Illustrated London News acompanharam in loco as operaçóes militares da guerra da Criméia, que teve a maior quantidade de imagens. Os retratos, dada a impossibilidade técnica de serem reproduzidospela imprensa na época, eram copiados através de litografias e publicados.

Ointeresse na produção e divulgação de material sobre guerra, em geral, foi descoberto pelos fotógrafos e pela imprensa ilustrada no Brasil em função do conflito com o Paraguai. Terminada a guerra, osjornais começaram, imediatamente, a divulgar imagens sobre o conflitofranco-prussiano que então se iniciava. Em termos de imagens, como se verá melhor na parte dedicada à imprensa ilustrada, bavia necessidade de uma guerra, qualquer uma.

Oregistrodaguerra doParaguaifoi de pequeno interesse para os war corresponsals europeus e norte-americanos. Apenas uma firma norte-americana sediada em Montevideo mandou correspondentes para registrar a guerra, e nãosóparatirar retratos como todos os outros fotografos que fizeram a campanba do Paraguai. Isso não quer dizer que náo havia interesse em imagens do confli- 
to na Europa. Ao contrário. Revistas francesas, como L'Illustration, Tour de Monde, entre outras, reproduziram em litografias, entre 1864 e 1870, abundante material a partir de fotos sobre a guerra. A imprensa inglesa e norte-americana publicava, desigual e esporadicamente, litografias feitas sobre fotos.

EM TENDAS E BARRACOS: OS FOTÓGRAFOS NO “TEATRO DE OPERAÇÓES”

Osfotógrafos seguiram os exércitos aliados pelos seis anos que durou o conflito, de 1864 e 1870, no Brasil, na Argentina e interior doParaguai. Durante todo esse tempo, fotógrafos que estiveram no “teatro de operaçóes” militares atuaram a partir de Uruguaiana, Corrientes e Rosário, na fase inicial da guerra; depois, no extremo suldoterritórioparaguaio, Tuiuti, Pasoda Pátria eTiü-cuê, acampandojuntoaos exércitos aliados; estiveram em Humaitá sitiada eocupada e, finalmente, em Asunción na última fase.

Devido à itinerância dos fotógrafos e às dificuldades de registro de suas passagens, nunca se saberá ao certo quantos e quais profissionais estiveram na guerra do Paraguai. A identificaçãodo material que chegou aos nossos dias também é problemática. Uma boa parte dos carte-de-visite permanece com autoria anônima. Autores dos mais conbecidos, como Esteban Garcia e sua equipe enviados por Bate \& Cia., têm diversas atribuiçóes duvidosas.

Enquanto a guerra desenrolou-se no Rio Grande do Sul, até a rendição da coluna invasora de Estigarríbia em Uruguaiana, em setembro de 1865, muitosfotógrafos gaúchos e uruguaiosforam favorecidos pela proximidade com ofront. É o caso, entre outros, de Luiz Terragno que retratou o imperador em Porto Alegre; e, em Montevideo, de Saturnino Masoni, que editou uma série de cópias com a imagem do Gal. Venancio Flores, presidente e comandante do exército uruguaio.

Montevideo, como porto de passagem, recebeu milhares de soldados da Aliança durante toda a guerra. Osestúdios de Desiderio Jouant, Chutte \&Brooks e Bate \& Cia realizaram centenas de retratos $^{15}$. Além disso, foram mencionados outros profissionais que traballsaram como retratistas na capital oriental durante a guerra, como Alfredo Vigouroux, Anselmo Fleurquin, Enrique Schikendantz, Martínezy Bidart, George Bate eJuan Wander Weyde. 
Osfotógrafos argentinos, ou que a partir da Argentina faziam seus negócios, também foram favorecidos pela proximidade com seus estúdios na primeira fase da guerra. É o caso, dentre outros, em Rosário, do alemáoJorge Enrique Alfed, e em Corrientes, de Pedro Bernadet ${ }^{16}$.

Depois da rendição da coluna de Estigarríbia, alguns prisioneiros paraguaios foram levados a Porto Alegre e fotografados pela iniciativa de um oficial brasileiro, cujo nome se perdeu. Ofotógrafo também é desconbecido. Uma dasfotos traz a legenda: "Soldado paraguaio Antonio Gomes, prisioneiro em Uruguaiana. Tem 21 anos de idade. Natural da vila de Jaguarão, no Paraguai. Mandei tirar este retrato em Porto Alegre, em 27 de abril de 1867". Como a rendição paraguaia ocorreu em 18 de setembro de 1865, este e os outros que compóem uma série de aproximadamente seis retratos de prisioneiros, atualmente na Biblioteca Nacional no Rio de Janeiro, esperaram sete meses para serem feitos.

O retrato de prisioneiros paraguaios parece ter se tornado prática comum entre os retratistas que atuaram ao lado das tro290 pas da aliança. Diversos profissionais, todos anônimos, retratavam oficiais e soldados paraguaios, vendendo as fotos em formato carte-de-visite.

Após a derrota dos aliados em Curupaití, em setembro de 1866, a guerra sofreu uma parada, em que os aliados trocaram seuscomandantes e reorganizaram seu exército. As operaçóes militares decisivas só seriam retomadas a partir de setembro de 1867. Esse período, em que os aliados permaneceram estacionados em Tuiutí, representou uma verdadeira benção para osfotógrafos: eram miIhares de potenciais clientes acantonados. Foi grande a produção nesse período. Centenas de carte-de-visite retratam os soldados aliados, com o acampamento como fundo. Ocotidiano do grande exército imobilizadofoi registrado por diversos fotógrafos anônimos: a rua do comércio, uma procissáo no acampamento, a guarda do general Caxias, soldados ao redor dofogo etc.

Outrasfotos, como a que leva a legenda "officiaes brasileiros, de volta de uma descoberta”, apesar de evidentemente arranjadas, são uma tentativa de se chegar perto da ação no front, ao retratar bomens que retornam de uma patrulba juntoàs linbas inimigas. 
Após a conquista de Humaitá, em julbo de 1868, a guerra mudou seu curso: uma série de vitórias aliadas foi o prenúncio dofim do conflito. Carlos Cesar, fotógrafo do Rio de Janeiro, esteve em Humaitá ocupada nesse ano, fazendo retratos de exterior e interior da igreja destruída na antiga fortaleza paraguaia enoacampamento brasileiro em Tuiu-cuê, fotografando oficiais brasileiros em suas barracase ranchos.

Ascrianças paraguaias, que disfarçadas de soldados com barba postiça e rifles de madeira lutaram na última fase da guerra, também foram retratadas. No Museu Histórico de Buenos Aires conservam-se as duas fotografias em formato carte-de-visite que mostram corpos lacerados de meninos, ao que tudo indica infantes sobreviventes das batalhas de Lomas Valentinas e Acostañu. Cuarterolo afirma que se trata do único exemplo que sobrevive do uso da imagem como "instrumento político" durante a guerra do Paraguai ${ }^{17}$. Isso devido ao emprego que foi dado aos retratos, utilizados como "prova" de que o regime de López não tinha o menor escrúpulo em sacrificar qualquer babitante do Paraguai para se manter nopoder.

Nofinal, numa Asunción ocupada, apareceu um inglêsradicado em Montevideo, Johm Fitzpatrick, que realizou fotografias da cidade, dos prisioneiros etc. Numerosas vistas da cidade foram também produzidas por fotógrafos anônimos, mostrando a estação de trens, a catedral etc.

A partir de 1869 e até 1870, aparece uma série de fotos tomadasnoParaguai, de autoria anônima, que mostrava opaís derrotado e os sinais do afastamento de López do poder: o palácio de López ocupado pela infantaria brasileira e com uma torre a menos, efeito dos bombardeios da esquadra imperial, a propriedade rural de madame Lynch em Patiño-Cue cercada de tendas do exército brasileiro, festas e comemoraçóes de militares, trincheiras aliadas etropasbrasileiras em manobras próximas à capital paraguaia.

Ofrancês PedroBernadet, que também traballhou em Corrientes, realizou, em Asunción, uma série de fotos do marechal López, de seu filbo Panchito, de madame Lynch e outros personagens entre 1865 e $1870^{18}$. Uma conbecida foto de Francisco López, taciturno, pouco tempo antes de sua morte, também foi de sua autoria. 
ESTEBAN GARCIA: FOTÓGRAFO DE BATE E CIA.

Adocumentaçãofotográfica daguerra do Paraguai, apesar do volume de retratos produzidos, ficou marcada pela iniciativa do estúdio efirma Bate \& Cia. de Montevideo, que mandou Esteban Garcia, um técnico uruguaio, para produzir uma série defotografias sobre o conflito entre abril e setembro de 1866.

Chegados ao Prata em 1859, os norte-americanos Bate estabeleceram-se comofotógrafos em Montevideo em junbo de 1861. O estúdio era de propriedade de George Thomas Bate e seu irmão, do qual não se conbece o prenome. A empresa tinha sucursais em Londres e em La Havana, ao que tudo indica a cargo do irmão de George Bate, que retornou à Inglaterra em $1861^{19}$.

No final de 1864 e início do ano seguinte, os fotógrafos de Bate \& Cia. registraram o bombardeio de Paisandu, cidade uruguaia que resistia às forças de Flores, apoiado por brasileirose argentinos. Seis imagens foram editadas com otítulo "Paysandú, 2 de enero de 1865" e postas à venda. O "Álbum de Paysandú", no Arquivo Histórico de la Armada Argentina, traz estas fotografi292 as e outras referentes ao episódio ${ }^{20}$.

Além dessa experiência, certamente os irmáos Bate conbeciam o trabalbo dos fotógrafos britânicos na guerra da Criméia e de Mathew Brady e sua equipe na guerra de Secessão. Em 1865, Wander Weyde passou a ser o proprietário de Bate \& Cia., que continuou mantendo o nome dos antigos proprietários.

Foi Wander Weyde, um químico belga, quem realizou as gestóes junto ao governo uruguaio para obtençáo de salvo-conduto a fim de que seusfotógrafos pudessem presenciar as operações do sudeste paraguaio. Apesar de náo ter caráter oficial, a expedição contou com auxílio de transporte das autoridades, obtendo, inclusive, a exclusividade de comercialização das fotos até seis meses depois de finalizada a guerra.

Embora a empresa fosse, na época, propriedade de Weyde, foi inegável a participaçáo dos Bate no projeto de fazer um registro da guerra. Esteban Garcia, omais bábil profissional da firma, chefiava os trabalbos, realizados entre maio e setembro de 1866, dezesseis meses depois de Paisandu ${ }^{21}$. Na verdade, operíodo em que Garcia esteve na guerra é algo nebuloso. Diversas fotografias que lhe fo- 
ram atribuídas têm datas posteriores a esse período. É o caso da foto que registra a saída do comboio do Marquês de Caxias de Tuiu-cuê, onde os aliados só chegariam em julbo de 1867.

Garcia deixou registrada a crueza da vida de trincheira: ossoldados e oficiais uruguaios, brasileiros e argentinos, bospitais e missas, prisioneiros paraguaios, baterias de artilharia, ofront com as linhas inimigas ao fundo, cadáveres paraguaios abandonados etc. Vale menção especial uma foto da Legião paraguaia, formada por Flores e integrada por paraguaios adversários de López.

Também dedicou atenção especial às paisagens que serviram de palco para os combates, como as ruínas da tomada de Itapiru (18 de abril de 1866) ou da batalha do Sauce, ou Boqueirão (18 de julbo de 1866).

Garcia conseguiu também oprimeiro "instantâneo" da guerra, ao retratar o coronel uruguaio León Palleja no exato instante que, ferido mortalmente na batallb a do Boqueirão, foi levado numa maca para a retaguarda. Soldados negros do batalbáo uruguaio Florida apresentam armas ao respeitado oficial, um dos melhorescronistas da primeira fase da guerra.

Mas a foto mais impressionante do conjunto, e de toda a guerra talvez, é a que se intitula "montón de cadáveresparaguayos" e que retratou precisamente corpos ressecados de soldados mal cobertos por panos, provavelmente vítimas insepultas dos combates de 24 de maio de 1866. Esta foto e a que mostra as crianças paraguaias sobreviventes dos combates de Lomas Valentinase Acosta-ñu, de autoria desconbecida, são, sem dúvida, os registrosfotográficos mais dramáticos da violência da guerra.

Garcia trabalhava com grandes negativos de colódio úmido sobre placa de vidro de 20 por $14 \mathrm{~cm}$, em precários laboratórios montados em tendas de campanba. Acampava junto às tropasuruguaias. Ao contrário de seus colegas, náoparece tertirado retratos de soldados, dedicando-se exchusivamente às "vistas da guerra".

No final de 1866, a primeira série de dezfotografias foi posta à venda, em cópias no tamanbo original do negativo. Ao que tudo indica, o empreendimento não teve muito êxito. Depois de Curupaiti (22 de setembro de 1866) e da morte de milhares de jovens nas trincheiras paraguaias, "a guerra se converteu em um 
assunto impopular para a sociedade rioplatense"22. Se asfotos não venderam como o esperado, pelo menos parece terem sido reproduzidas em volume considerável, inclusive em formato carte-devisite, até muito tempo depois da venda do estúdio.

Raras coleçóes particulares da época nãotrazem pelo menos uma das fotos tiradas por Bate \& Cia. As coleçóes pessoais de Mitre e de D. D. Pedro II, por exemplo, não são exceções. A última possui ó álbum "La guerra contra el Paraguay. Bate \& Cia. W, Montevideo", com 12 fotos.

Em fevereiro de 1867, Weyde anunciou a venda do estúdio. O novo proprietário, de posse dos negativos do Paraguai e Paisandu, anunciou uma nova coleçáo de 21 vistas da guerra. Os atores mudavam, os negócios prosseguem.

\section{O FOTÓGRAFO NO ACAMPAMENTO}

A novidade para os fotógrafos itinerantes envolvidos na cobertura da guerra, era, digamos, a situaçáo de campo. Acostumados às condiçóes de vida em cidades, tiveram que se transportar e ao seu equipamento em carros de boi por milhares de quilômetros até os acampamentos das tropas, onde se acomodavam como podiam em tendas ou em desmantelados barracos de palba, meio cobertos por lonas. Uma litografia, feita sobre fotografia, e publicada na Vida Fluminense em 1866, dá uma imagem das duras condiçôes de vida dos fotógrafos no pobre rancho descrito como "Estabelecimento de Erdmann \& Catermole", na ilha Serrito.

Os profissionais dos carte-de-visite estabeleciam-se próximos às "ruas do Comércio", existente nos acampamentos das tropas da Aliança durante quase toda a guerra. Recebiam a clientela em seus precários estúdios ou indo até suas tendas e barracas. Àsfotosfeitas em estúdio, com cortinas com desenhos geométricos gregas, colunas e balaustradas greco-romanas, agora se somavam aquelas feitas com fundo natural e de inspiração guerreira: tendas, fogueiras, sarilhos, espadas penduradas, enfim, o acampamento e suas rústicas condições. Outros fotógrafos, como os enviados por Bate \& Cia. de Montevideo em 1866, montaram sua tenda em pleno acampamento de tropas em Tuiuti,junto a um posto de observaçãoelevado, mangrullo. 
Se, para profissionais brasileiros ou que atuavam no Brasil, a situação de fotografar numa guerra era uma novidade, o mesmo náo pode ser dito dos argentinos. Existia, na Argentina, uma tradiçãode registros fotográficos de conflitos internos, anterior à guerra doParaguai23. De 1853 a 1862, durante a hutados estados argentinos (comos Federalistas da ConfederaçãoArgentina, com capital nacidade de Paraná, disputando o controle da naçáo com os Unitários do Estado de Buenos Aires, sediados na cidade de mesmo nome), daguerreotipistas efotógrafos registraram continuamente retratos de caudilhos, montoneros insurretos e exércitos regulares.

As primeiras fotografias tomadas em Buenos Aires já podiam ser consideradas fotografias militares, visto que uma delas mostra o exército de Urquiza entrando na cidade após a derrota de Rosas e outra é o retrato do vencedor ${ }^{24}$. Oformato carte-de-visite veio acentuar a produção de retratos militares, mas náofundou o gênero, como no Brasil.

Além de saírem do estúdio das cidades e de se transportarem para os acampamentos militares, osfotógrafos da guerra souberam incorporar novidades na composição de seus trabalbos, que ganbavam em realismo, deixando de ser apenas "retratos". Até o mais prosaico carte-de-visite passava, por força do momento, a adquirir significado especial como um documento bistórico.

\section{OS RETRATOS DA GUERRA}

Até a guerra do Paraguai, nunca se tinba visto imagens de tropas do Brasil combatendo, muito menos no exterior. Na Argentina e no Uruguai já se conbeciam daguerreótipos e fotografias de episódios militares da conturbada vida política desses dois paúses entre as décadas de 1840 a 1860. Opúblico desses paúses podia ver, por meio das fotografias, não só as tropas nacionais mas também o "inimigo".

Mesmo explorando gêneros e temas de fotografiasjá consolidados, como retratos e paisagens sobre temas militares, o conjunto de material produzido apresenta significativas diferenças em relação à produção anterior ou dos tempos de paz. Qualquer que fosse o assunto, a guerra como que transformou a qualidade domaterial produzido. 
Astentativas, ainda que boje nospareçam precárias, de se captar a ação nas linbas de combate são significativas. As fotos de “officiaes brasileiros, de volta de uma descoberta", de um oficial argentino, pretensamente em combate e armado de sabre e revólver, ou o retrato da morte do coronel Palleja são tentativas de fazer o registrofotográficoganhar agilidade, escapandoda previsibilidade e imobilidade do estúdio.

Osfotógrafos abandonaram uma certa rigidezna composição dasfotos em ambientesfechados e passaram, dadas as condiçóes, a fazer retratos em campo aberto, em meio a tendas, baterias de canhóes, cadáveres, barracas e soldados. Muitasfotos, infelizmente anônimas, fizeram do cotidiano do acampamento guerreiro o seu fundo. Temos fotos que, ao contrário do que era feito na época, cultivavam uma realidade sem retoques, com os personagens em situações apresentadas como espontâneas, não em poses rígidas.

Para a fotografia da época, cujo enquadramento e composição eram regidos pela lógica de composição da pintura acadêmica, aquilo era uma mudança. Não era uma alteração no panora-

296 ma internacional dafotografia, uma vez que traballbos como o de Mathew Brady sobre a guerra civil norte-americanajá traziam muitas dessas "novidades". Era uma inovação, no entanto, no tipo de fotografia que se fazia no cone sul nas décadas de 1850 e 60.

Em termosformais, a guerra do Paraguai arejou as composições dasfotos maso assunto tornou-as mais pesadas, mais 'históricas". De qualquer forma, os profissionais envolvidos, pelas condições e pelo assunto, foram forçados a adotar soluções originais para uma situaçãonova, que a maioria delesnunca bavia fotografado: retratar civis em trajes domingueiros num estúdio era bem diferente de retratar soldados no campo de batalha.

As particularidades do acompanbamento da guerra faziam osfotógrafos, principalmente os que atuavam próximos aofront, a repensarem alguns dos fundamentos do oficio: como trabalhar com o instável colódio no calor e umidade, como fazer a composição das fotos for a do estúdio, comofazer retratos "naturais" de soldados e paisagens, comofotografar novas poses e assuntos pedidos pelos próprios soldados etc. 
Mesmo os simples retratos ganbavam dramaticidade. Muitos dos retratados, a maioria oficiais que podiam pagar para terem sua imagem imortalizada, morriam pouco tempo depois em combate ou por doenças. A imprensa ilustrada, principalmente no Brasil e menos na Argentina e no Uruguai, reproduzia litografias dos bravos que morriam baseados em cópias de carte-de-visite. Os heróis agora tinham um rosto e os mortos deixavam de ser anônimos. Aindividualização das vítimas da guerrafazia seuscustos bumanos parecerem maiores.

Afoto ganbava importância, enfim, como última imagem dos muitos que não voltaram. Os carte-de-visite transformaram-se em testemunbos de que aquelas pessoas, tão comuns, conviveram, no entanto, com algo extraordinário. Seu valor como objeto de afeto e documento bistórico muda, se comparado aos realizados em tempo de paz.

Os retratos transformaram-se em algo novo. Asfotos de prisioneiros paraguaios, feitas em Porto Alegre e mencionadas atrás, são um exemplo disso. A visão do "inimigo", subitamente transformado em serhumano, tocava até os mais duros defensores da guerra. Ocarte-de-visite transforma-se em documento bistórico, em testemunbo e denúncia. Como neste caso, muitos dos outros registros, de retratos a paisagens, feitos por evidente interesse comercial, tornaram-se, involuntariamente, documentos de crítica da guerra.

Isso porque, ao mesmo tempo que registravam o heroísmo dos combatentes, registravam também o acampamento mambembe, a precariedade dos exércitos, os bomens desmazelados, os milhares de mortos, a miséria, enfim, de todos os contendores.

Avisáo crítica trazida pelos registros fotográficos e a impopularidade do conflito devido ao número de baixas, ausência de vitórias e o início dos recrutamentos compulsórios, já a partir de setembro de 1865, ajudam a explicar o pouco sucesso de ediçóes defotos exchusivamente dedicadas à guerra, como de Bate $\&$ Cia. Já bastavam as notícias textuais do conflito interminável.

As imagens da guerra não permitiam ufanismo, mesmo as de sua fase inicial. Vendo o inimigo prisioneiro, ou em pilbas de cadáveres, só se conseguia sentir pena. Longe de emularem os espíritos guerreiros, as fotosfaziam desejar a paz. 
Asfotos do conflito também inauguraram a possibilidade de sua utilizaçáo como propaganda de guerra. Os registros da guerra do Paraguai, mesmo aqueles que foram utilizados em propaganda anti-López, iam muito além dos seusfins ideológicos imediatos. Denunciavam a estupidez da guerra.

Não se deve subestimar a importância do registrofotográfico, em formato carte-de-visite ou por meio de sua cópia e publicação em litografias pela imprensa da época, na formação de uma opiniáo pública contrária à continuidade do conflito nos países da Aliança, apenas um ano depois de seu início.

A crueza do assunto, em resumo, fez com que gêneros de fotografias já conbecidos, como retratos e paisagens, se transformassem em algo novo. A guerra "arejou" a fotografia em termosformais, dando-lhe liberdade de composição e escolha de assuntos novos. Aotrazer a fotografia para ocampodonoticiário, fezcom que deixasse de circular apenas como prova de afeto entre pessoas.

A guerra do Paraguai estabeleceu a importância da utilização jornalística da fotografia de guerra, mesmo por intermédio de 298 cópias, em litografias, dos originais, no Brasil, na Argentina e, num grau menor, no Uruguai. A imprensa ilustrada, a gravura e a pintura devem muito à fotografía do período, utilizada por quase todos os autores do período como referência.

Mas a fotografia também desenvolveu uma linguagem própria, por meio dos álbuns, baseada na agilidade do registro e de sua rentabilidade comercial. Enquanto assunto, deixou de ser uma coisa familiar e privada e transformou-se em coisa de interesse público. A guerra, sem dúvida, ampliou os limites de produção e consumo da fotografia no cone sul.

A guerra do Paraguai com a Tríplice Aliança ocorreu contemporaneamente à descoberta de processos técnicos que permitiram, no período, uma oferta de imagens até então inédita, por meio da imprensa ilustrada e da gravura, da pintura e dafotografia.

Resultado de projetos nacionalistas oficiais e do próspero mercado de imagens, a iconografia da guerra do Paraguai não inovou apenas em trazer a guerra para junto da opiniáo pública. A rentabilidade comercial do assunto inaugurou a cobertura visual de conflitos, ao mesmo tempo que lançou e viabilizou as téc- 
nicas, a fotografia e a litografia, que possibilitariam sua continuidade. A pintura, apesar das altas taxas de visitação das exposiçóes, esteve longe de poder acompanhar a rapidez com que se produziam imagens em estúdios fotográficos ou em redações de jornais. Tornava-se impossível, aos governos, evitar a "subversáo imagística" trazida pela fotografia e pela imprensa ilustrada. Agora, a sociedade tinba outras imagens para contrapor à iconografia "oficial".

Diante da massa desordenada de informações e de novos assuntostrazidos pela fotografia, as pinturas acadêmicastransformaram-se em alegorias destinadas a prédios e repartições públicas. Não estiveram ao alcance do público durante a guerra a não ser em exposiçóes na corte e em feiras internacionais.

Talvez a maior herança deixada por essa "febre de imagens" do período foi, primeiramente, esta possibilidade do seu uso jornalístico, ocorrida simultaneamente com uma certa "laicização", no sentido da sua maior independência em relação às representaçóes quase oficiais da pátria. Não eram só os governos, afinal, os responsáveis pela formulação do que seriam as característicasnacionais desses países.

Apintura acadêmica subvencionada pelo Estado perdeu sua begemonia de uma forma brusca, comoforma de representação da nação. Extratos médios da população urbana, tecnicamente qualificados e politicamente excluídos, buscavam, como no caso brasileiro, formas de representatividade e cidadania num paúsreal, longe das idealizaçóes classicistas ou românticas. $O$ "realismo" pretendido pela fotografia combinava com a tarefa de levantar, cientificamente, os problemas nacionais a que pretendia o pensamento progressista da época.

\section{NOTAS}

${ }^{1}$ KOSSOY, Bóris. Origens e expansão da fotografia no Brasil. Século XIX. Funarte, Rio de Janeiro, 1980, p. 29.

${ }^{2}$ VASQUEZ, Pedro. D. D. Pedro II e a Fotografia. Rio de Janeiro, Fundação Roberto Marinbo e Companbia Internacional de Seguros/Editora Index Imprinta, Rio de Janeiro, 1986, p. 19. VASQUEZ, Pedro. “A Fotografia no Brasil do século dezenove-do Pará a São Paulo”. In A Fotografia no Brasil do século XIX. São Paulo, Pinacoteca do Estado de Sáo Paulo, 1993. 
${ }^{3}$ SONTAG, Susan Apud Amaral, Aracy Abreu. "Aspectos da comunicação visual numa coleção de retratos”. In MOURA, Carlos Eugênio Marcondes de (org.). Retratos quase inocentes. Sáo Paulo, Ed. Nobel, 1983, p.118.

${ }^{4}$ KOSSOY. op. cit. p. 42.

${ }^{5}$ Idem. p. 38 e VASQUEZ. op. cit., p. 20.

${ }^{6}$ KOSSOY. op. cit., p. 38 e VASQUEZ. op. cit., p. 20.

${ }^{7}$ Cuarterolo, Miguel Angel. "Una Guerra en el Lienzo-Lafotografia ysu influencia en la iconografía de la Guerra del Paraguay”. In El Arte entre lo Públicoylo Privado. VIJornadas de Teoría e Historia de las Artes. Buenos Aires, 1995, p. 95. CASABALIE, Amado Becquer e CUARTEROLO, Miguel Angel. Imágenes del rio de la Plata. Crónica de la fotografia rioplatense. Editorial del Fotografo, Buenos Aires, 1985.

${ }^{8}$ GESUALDO, Vicente. Historia de la Fotografia en America. Desde Alaska hasta Tierra del Fuego en siglo XIX. Cap. Paraguay. Buenos Aires, Editorial Sui Generis, 1990, p. 234.

${ }^{9}$ KOSSOY. op. cit.

${ }^{10}$ FERREIRA DE ANDRADE, Joaquim Marçal. “A Coleção do Imperador”. In Biblioteca Nacional, A Coleção do Imperador: fotografia brasileira e estrangeira no século XIX (catálogo). Biblioteca Nacional e Centro Cultural Banco do Brasil, Rio de Janeiro, 1997, p. 02.

${ }^{11}$ Idem e VASQUEZ, op. cit.

${ }^{12}$ CUARTEROLO. op. cit., p. 98.

${ }^{13}$ LUQUI-LAGLEYZE,Julio M. "Uniformología y fotografia antigua: una felizalianza recíproca”. In Ilo. Congreso de Historia de la Fotografia. Organizadoporel Comite 300 Ejecutivo Permanente de Congresos de Historia de la Fotografia en la Argentina con el auspicio de la Federacion Argentina de Fotografia FA.F. y el Circulo Medico de Vicente Lopez. Ed. Mundo Técnico S.R.L., Buenos Aires, 1994, p.150.

${ }^{14}$ LUQUI-LAGLEYZE. op. cit., p. 150.

${ }^{15}$ CUARTEROLO, Miguel Angel. "Iconografía de Guerra-Fotografías de la Triple Alianza 1865-1870”. In Memoria Io. Congreso de Historia de la Fotografia. 23-24 mayo 1992. Florida-Pcia. Buenos Aires, p. 57.

${ }^{16}$ CUATEROLO. op. cit., p. 95.

${ }^{17}$ CUARTEROLO. op. cit., p. 58.

${ }^{18}$ GESUALDO. op. cit., p. 234.

${ }^{19}$ CUARTEROLO. op. cit., p. 55.

${ }^{20}$ LUQUI-LAGLEYZE, Julio M. e LUX-WURM, Mirta S. Larrandart de. El álbun del bombardeo de Paysandú de la colección del Comodoro D.José Murature (18641865), Congreso de Historia de la Fotografia. Organizadopor el Comite Ejecutivo Permanente de Congresos de Historia de la Fotografia en la Argentina con el auspicio de la Federacion Argentina de Fotografia FA.F. y el Circulo Medico de Vicente Lopez. Ed. Mundo Técnico S.R.L., Buenos Aires, 1994, p.129.

${ }^{21}$ CUARTEROLO. op. cit., p. 55.

${ }^{22}$ CUARTEROLO. op. cit., p. 97.

${ }^{23}$ LUQUI-LAGLEYZE. El álbun..., Uniformologia..., op. cit., p. 150.

${ }^{24}$ Idem. 

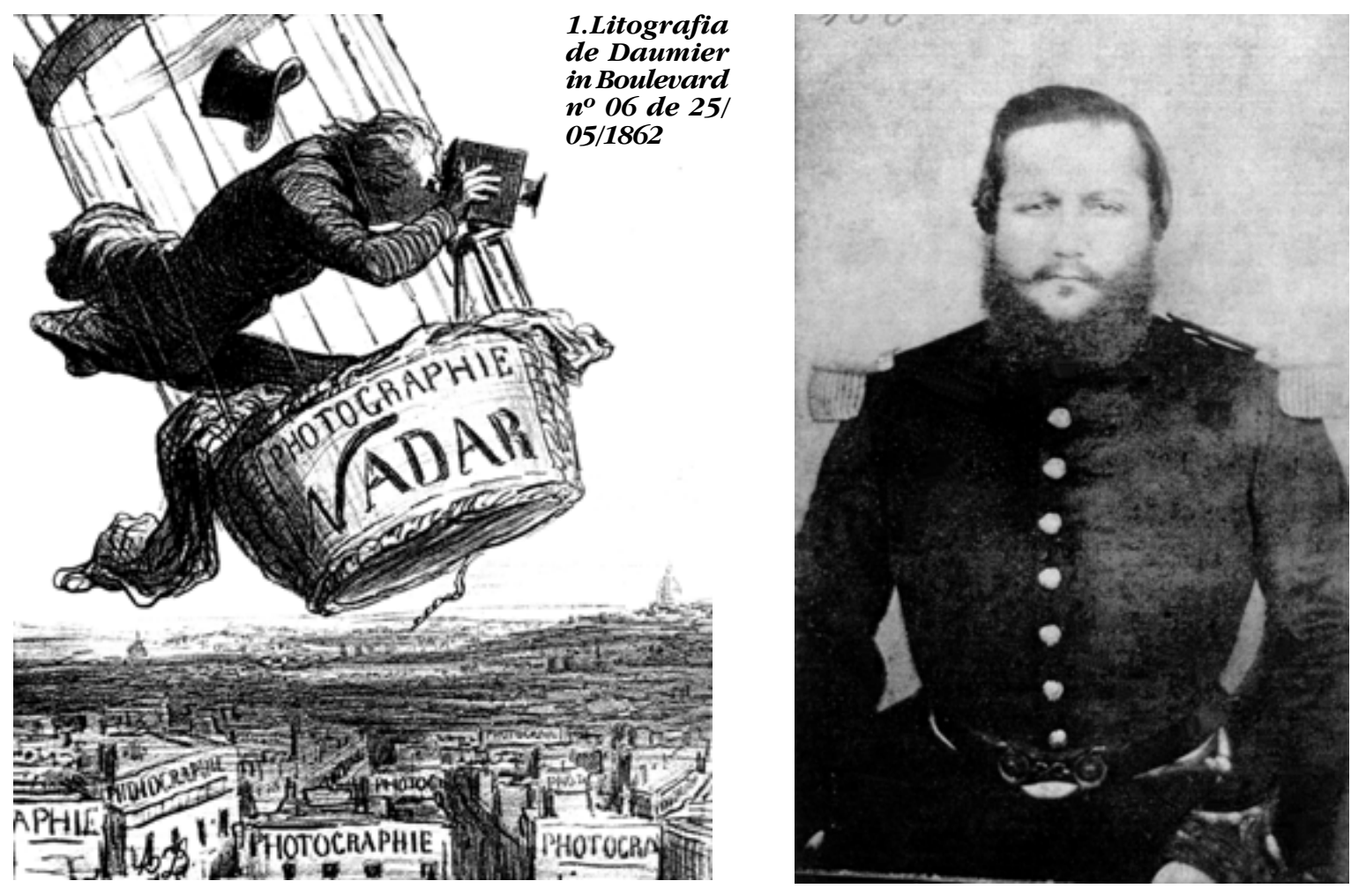

2. Autor desc.

(circa 1860):

carte-de-visite

com retrato

em albúmem

deFranciscos.

López. IHGB

RJ. 


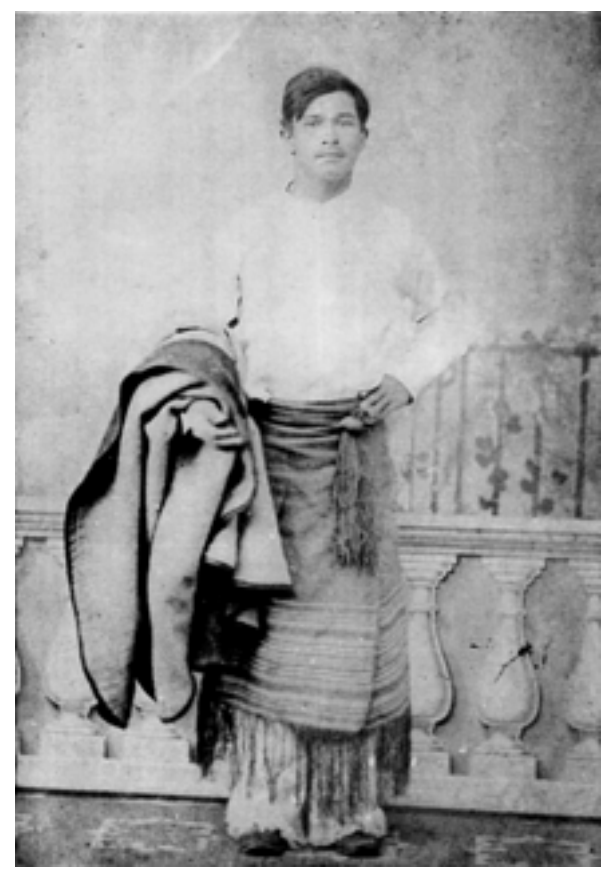

3. Autor desc. (1867): carte-de-visite com retrato do paraguaio Antomio Gomes. Biblioteca Nacional Rio deJaneiro.
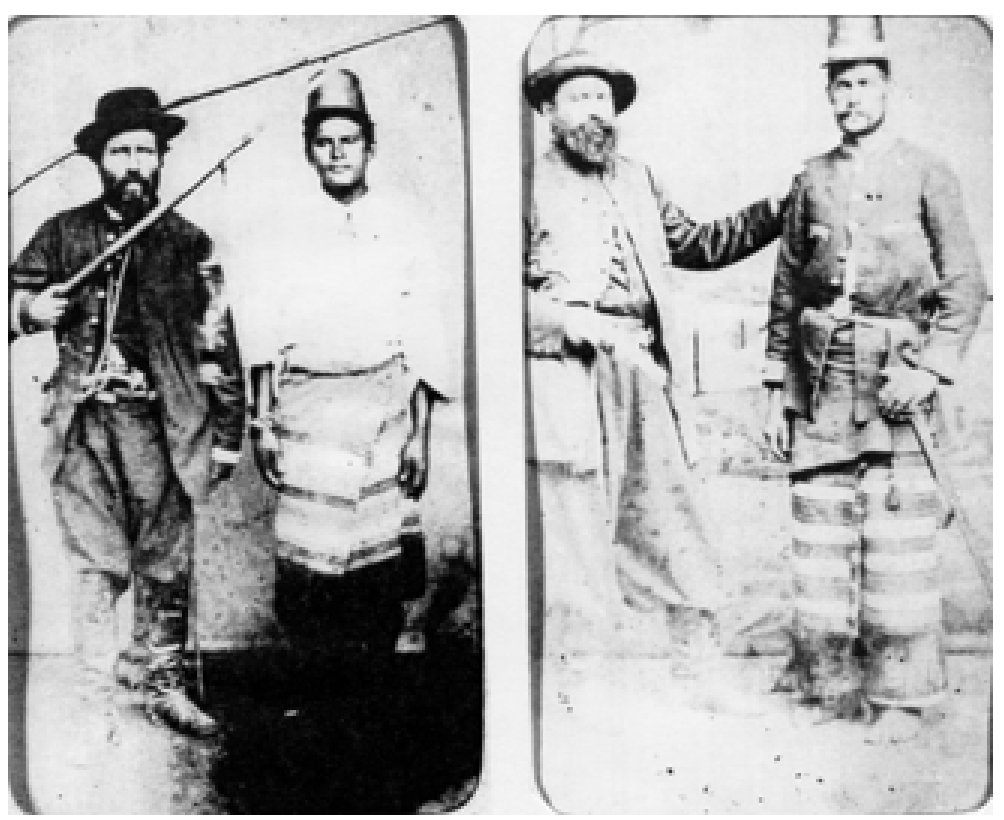

4.Autor desc. (circa 1867): dois cartes-de visite mostrando soldado e oficial paraguaios capturados por oficiais brasileiro e argentino respectivamente. Biblioteca Nacional Rio deJaneiro. 
5.Autor desc. (circa 1867): procissão no acampamento em Tuiutí Biblioteca Nacional Rio de Janeiro.

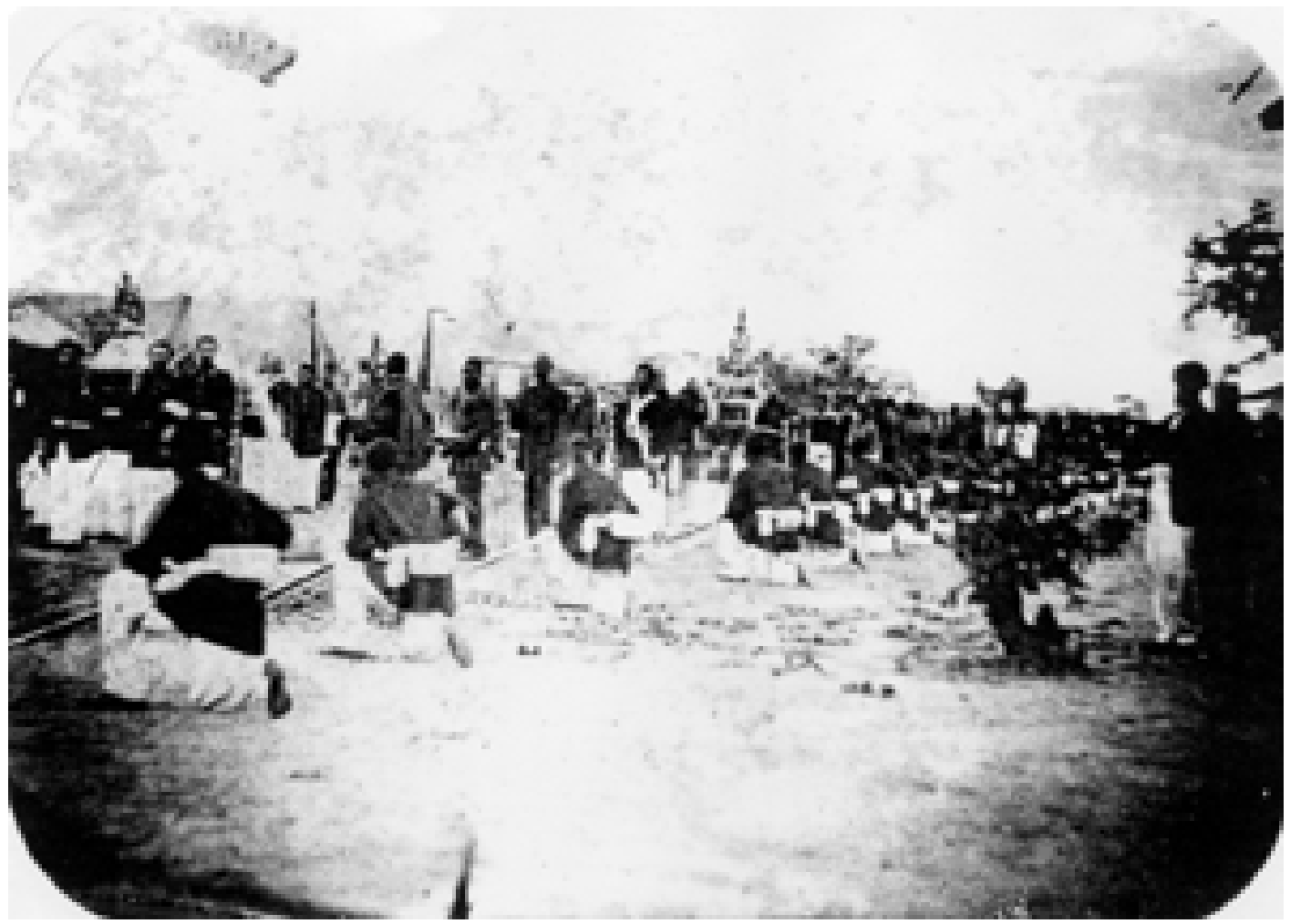

w 
జ

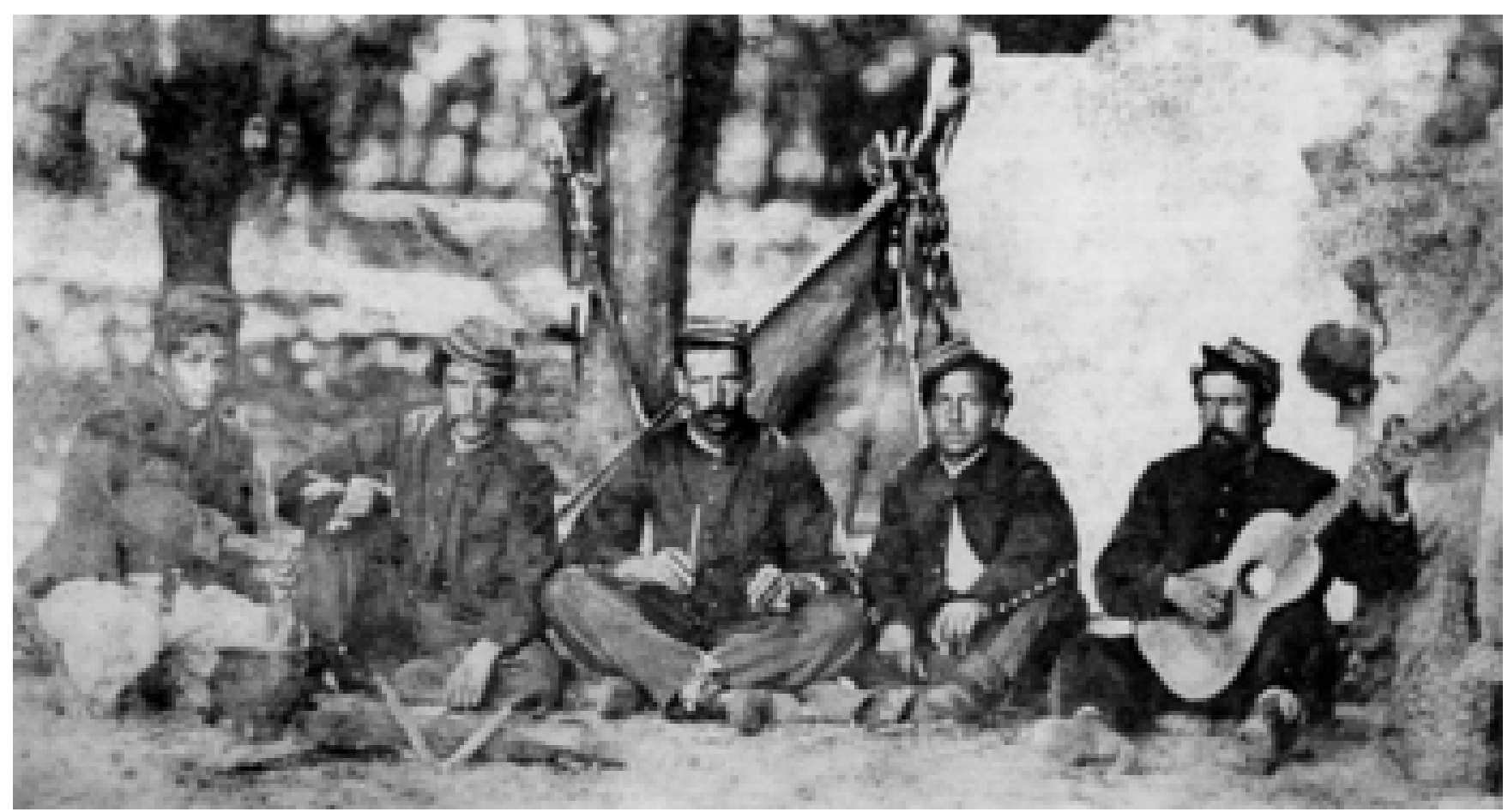

6.Autor desc. (circa 1867): oficiais argentinos em Tuiutí. Biblioteca Nacional Rio de Janeiro. 
7.Autor desc. (circa 1869): palácio dos López ocupado portropas brasileiras.

Biblioteca Nacional Rio de Janeiro.

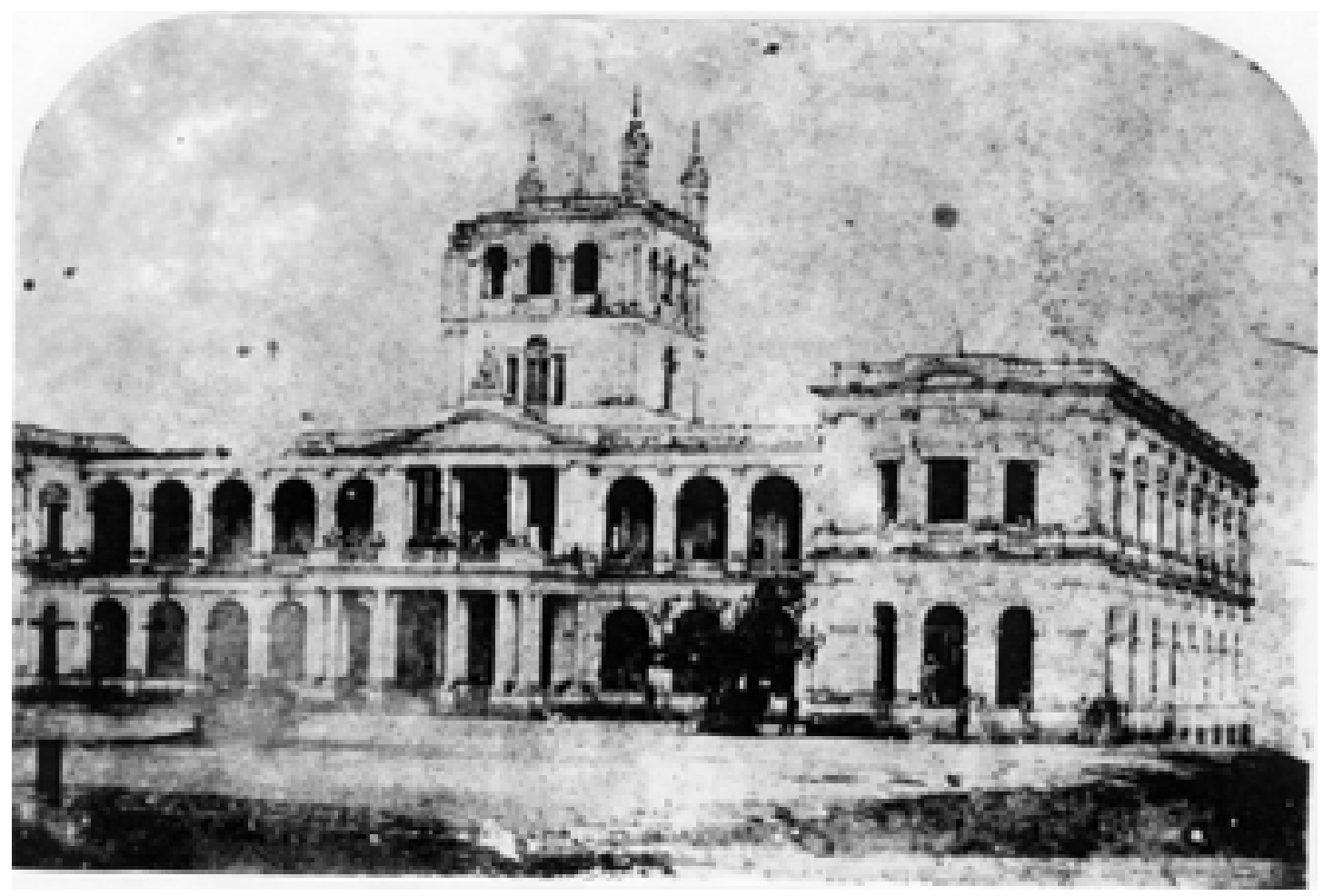

vi 


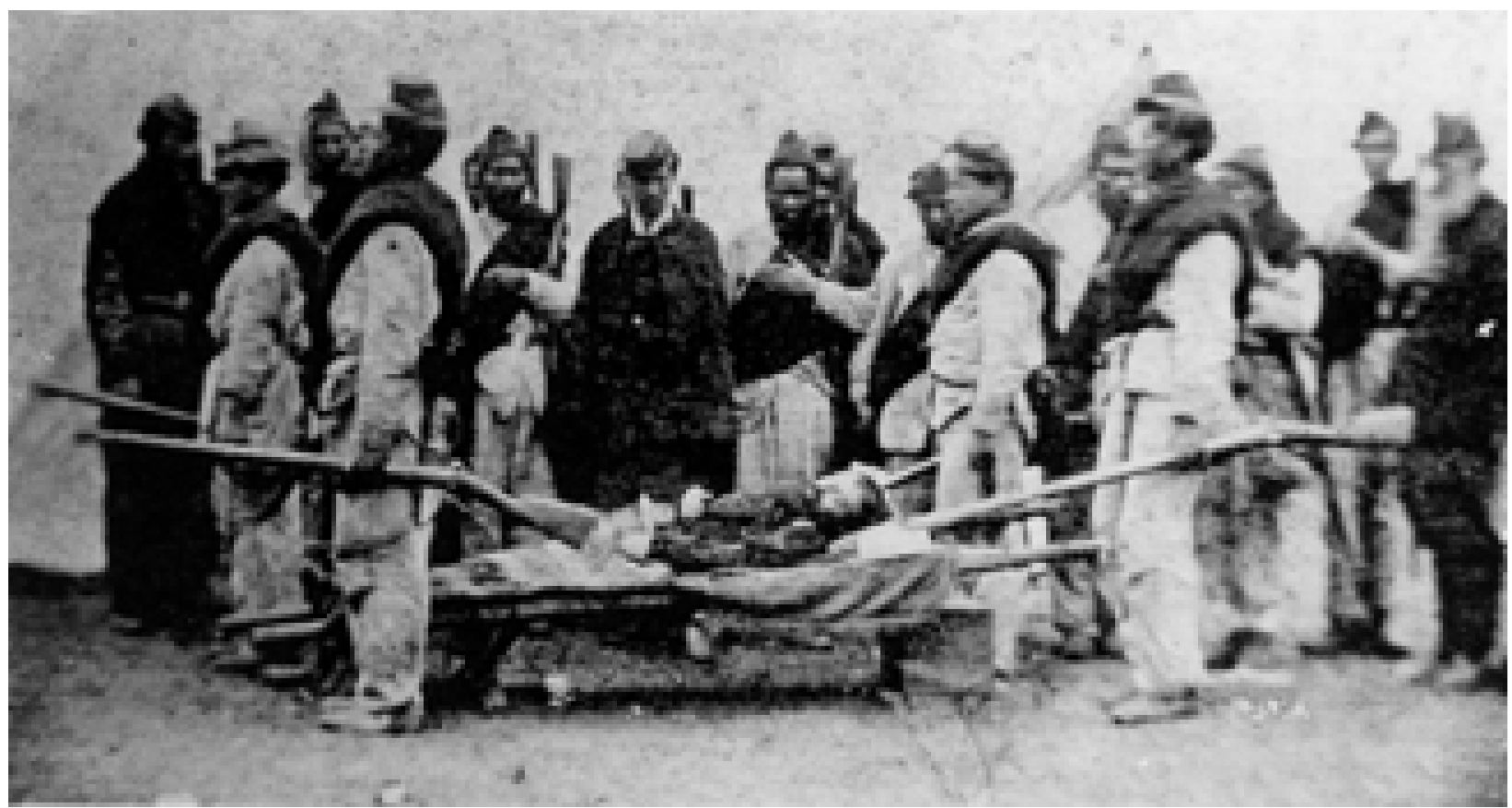

8.Esteban Garcia (1866): a morte do cel. León Palleja. Biblioteca Nacional Rio de Janeiro. 
9. Esteban Garcia (1866): montón de cadáveres paraguayos. Biblioteca Nacional Montevideo.

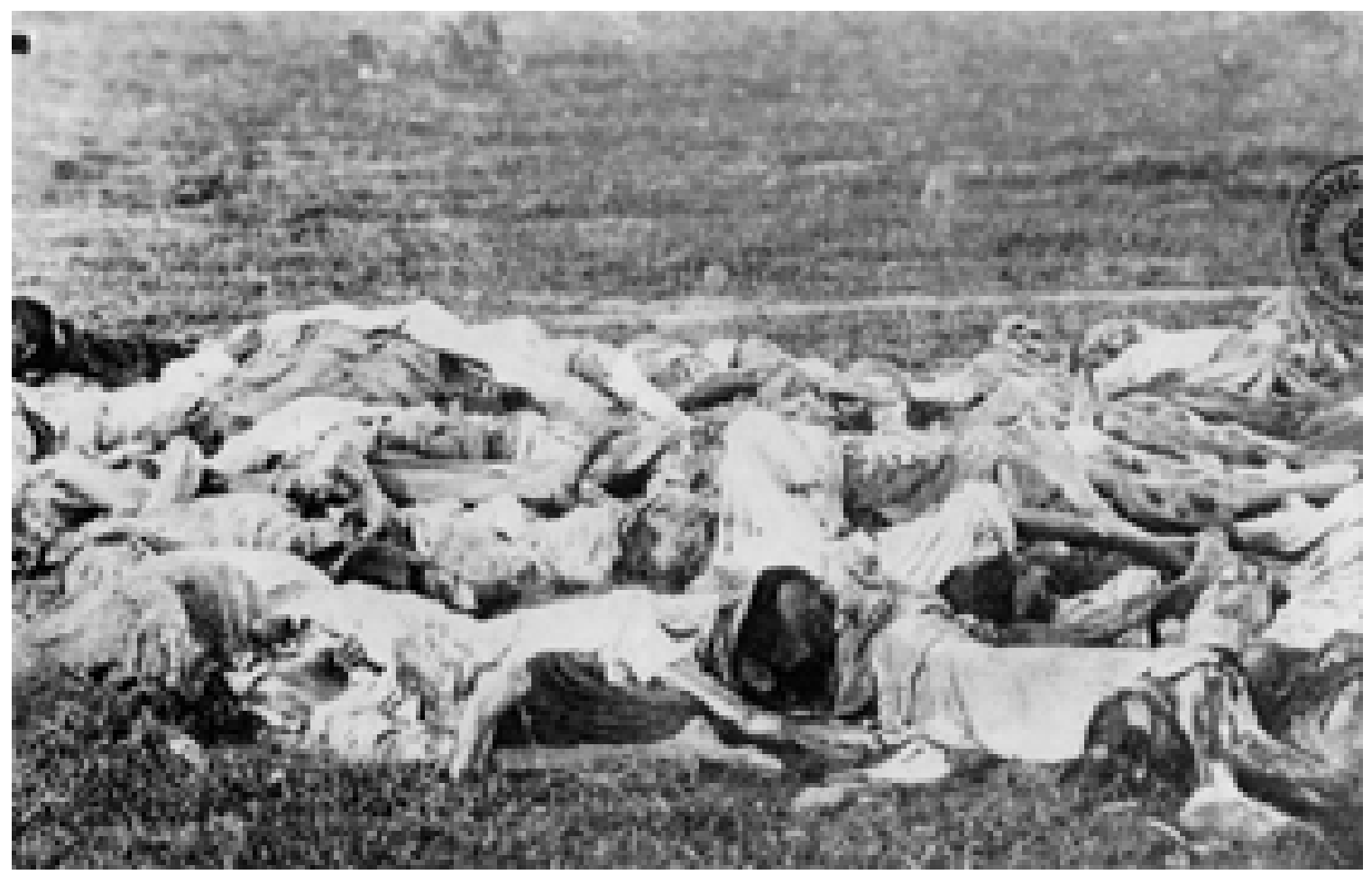




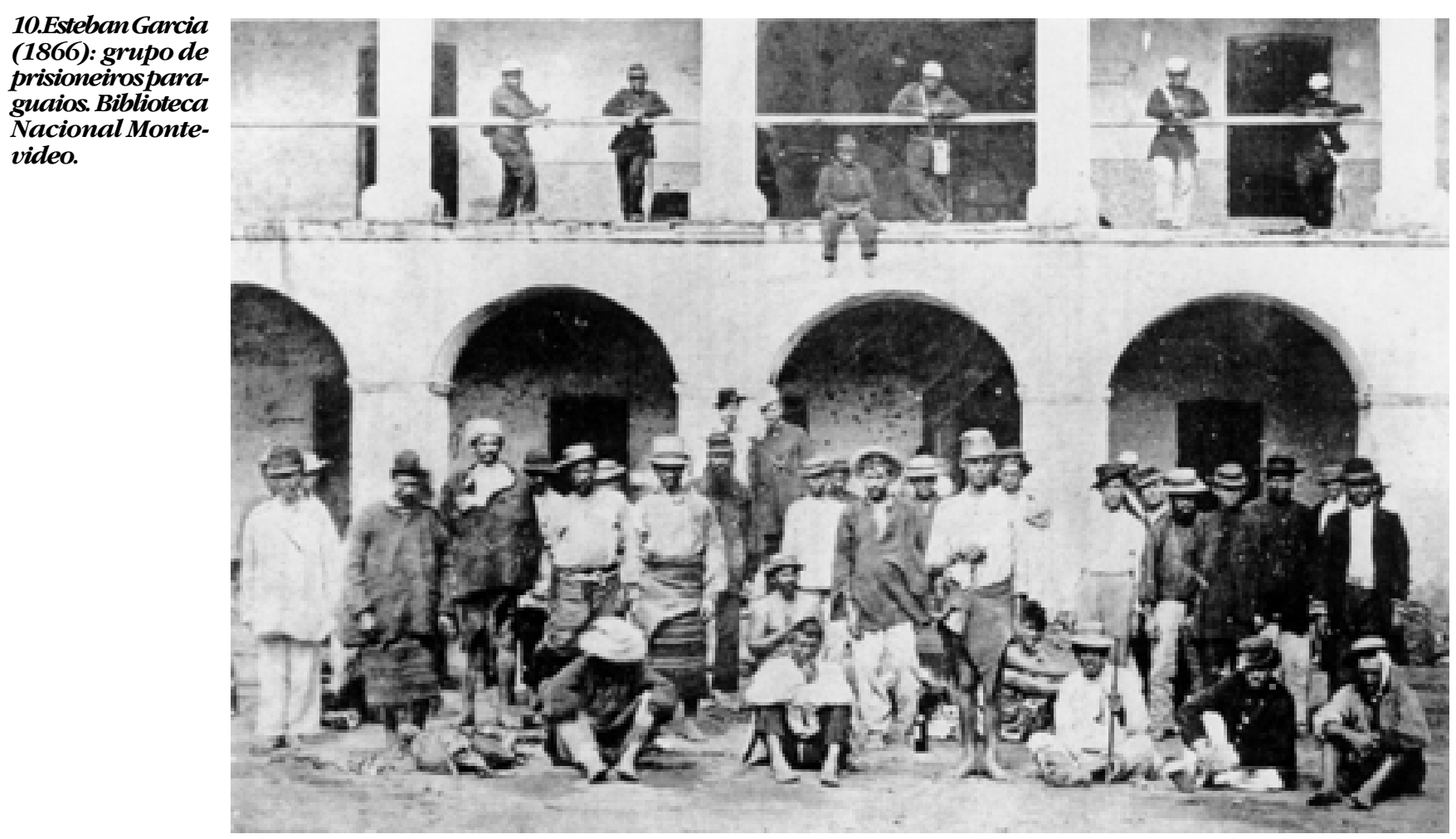


11.Esteban Garcia (1866): tenda da equipe de fotógrafos de Bate \& Cia. Junto a um posto deobservaçãomilitar. Biblioteca Nacional Montevideo.

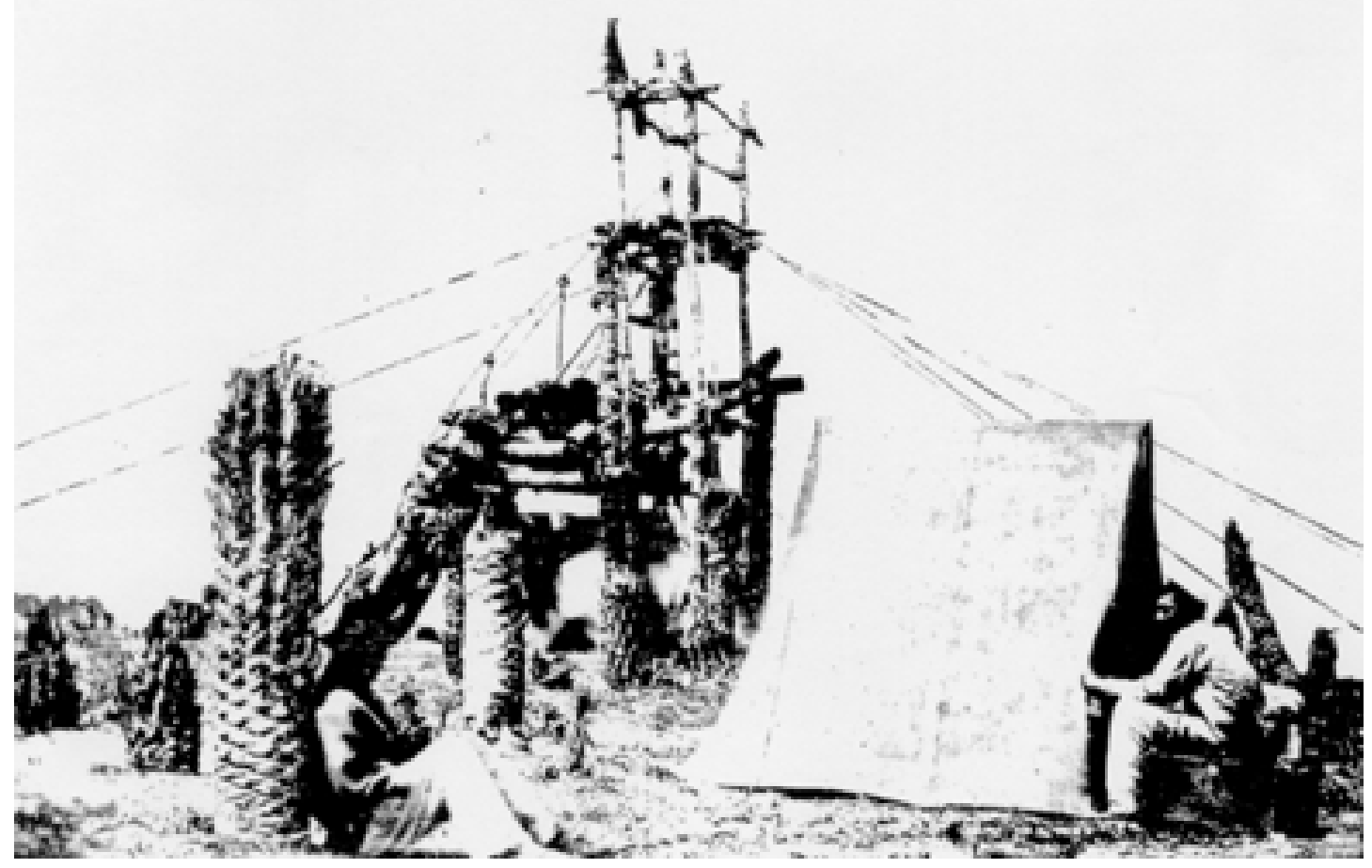


